\title{
OCULO-VISUAL STATUS OF NEWLY EMPLOYED WORKERS IN A TERTIARY INSTITUTION IN NIGERIA
}

\author{
J.A EBEIGBE \\ Department of Optometry, Faculty of Life Sciences, University of Benin, Benin City, Nigeria
}

DOI: http://dx.doi.org/10.4314/gmj.v49i4.5

Correspondence to: Dr Jennifer A Ebeigbe

Email: jennifer.ebeigbe@uniben.edu

Conflict of Interest: None declared

\section{SUMMARY}

Background: Visual impairment due to ocular diseases is a significant public health problem in many parts of the world including Nigeria. Worldwide, more than one billion people suffer from poor vision because they do not have the eyeglasses they need. Uncorrected refractive errors are a major cause of global disability and drastically reduce productivity, educational opportunities, and overall quality of life. Data is scant on pre- employment visual screenings in Nigeria because not many companies or employers of labor set this as a requirement for job placement. Objective: The purpose of this study was to report the oculovisual findings of new workers seen at a tertiary eye clinic.

Method: Descriptive study. Two thousand one hundred records of newly employed staff of the University of Benin, Nigeria, who were employed between November 2011 and August 2014 were reviewed. They were examined at the Optometry Clinic of the University. Of the 2100 case notes reviewed, 1203 (57.28\%) were males and 897 (42.71\%) were females. Age ranged from 23 to 65 years with a mean age of $43 \pm 2.1$ years.

Results: Refractive errors $25 \%$ and presbyopia $42.1 \%$ were the main visual problems recorded. The most common refractive error was hyperopia $26.8 \%$, followed by astigmatism $21.3 \%$ and myopia 9.6\%. Ocular conditions that were common among the workers were conjuctivitis $36.6 \%$, corneal disorders $25.2 \%$ and infection $21.1 \%$.

Conclusion: Mandatory routine eye test is advocated for new workers, especially those in establishment or companies were good vision is paramount to increased efficiency and productivity.

Keywords: Vision, workers, employment, eyes, screening.

\section{INTRODUCTION}

Most people will agree that vision is a critical aspect of many jobs. Whether the job involves visual inspection and quality control, sorting things by color or making critical life and death decisions such as when driving, vision can be very important for safe and effective job performance. ${ }^{1}$ Despite these facts, vision requirements for specific jobs are seldom specified by employers. Until it was stopped by the United States Supreme Court on June 22, 1999, vision requirements for commercial drivers, police officers and firefighters were being targeted for discrimination lawsuits. ${ }^{2}$ In some cases, organizations that posted vision qualifications, such as "20/40 vision required," were pressured to eliminate these requirements. ${ }^{3}$ In Nigeria, visual specification before employment is not mandatory.

Worldwide, more than one billion people suffer from poor vision because they are not corrected for one form of refractive error or the other. ${ }^{4}$. Uncorrected refractive errors are a major cause of global disability and drastically reduce productivity, educational opportunities, and overall quality of life. ${ }^{5,6}$ The problem persists most prevalently in low-resource settings even though prescription eyeglasses serve as a simple, effective, and largely affordable solution. ${ }^{7}$

Vision problems place a substantial burden on individuals, caregivers, health-care payers and the economy. ${ }^{8-10}$ Although regular comprehensive eye examinations are essential for timely treatment of eye disease to maintain vision health, previous studies ${ }^{11-13}$ have shown that substantial percentages of persons do not seek eye care, despite having visual impairment. In a Nigerian study to assess barriers to utilization of eye care services in rural communities, Sixty-eight per cent of the sample population was found to have never gone for an eye examination in a hospital. ${ }^{14}$ The study also reported ignorance and cost to be the highest barriers to utilization of eye care services. 
To ascertain why adults aged 40 years and above with moderate-to-severe visual impairment did not seek eye care in the preceding year, the center for disease control (CDC) USA, analyzed data for 21 states from 2006--2009 in the Behavioral Risk Factor Surveillance System (BRFSS) surveys. It was reported that eye-care cost or lack of insurance (39.8\%) and perception of no need $(34.6 \%)$ were the most common reasons given for not seeking eye care. Among those aged 40 to 64 years, cost or lack of health insurance was the most common reason $(42.8 \%)$ while among those aged 65 years and above, the most common reason was a lack of felt need $(43.8 \%))^{15}$

In Nigeria and generally in Africa, people do not often go for routine medical or eye examination. The vast majority of people attend hospitals when the condition is worsened or after trying all sorts of self-medications to no avail. ${ }^{14}$ Visual impairment and blindness due to ocular diseases is a significant public health problem in many parts of the world including Nigeria. ${ }^{8,16}$ The problem of low uptake of eye care services in developing countries has been given lower priority compared to the need for resource provision. Evidence shows that even when eye care services are available, they are under used by potential beneficiaries. ${ }^{17-20}$

Data is scant on pre- employment visual screenings in Nigeria and other parts of the world because not many companies or employers of labor set this as a requirement for job placement. Most companies ask for medical screening of which vision test is just a small part of. In Nigeria, most private companies and government establishments that do require medical screening before job placement do not place emphasis on vision tests, which is usually just one item on the medical form. As such, any medical personnel, who most times is not an Optometrist or Ophthalmologist, would usually tick the required field as 'adequate', without the candidate actually going through an eye examination.

The Department of Optometry in the University of Benin advised management on the need to include a mandatory eye test as part of the medical investigations undergone by newly recruited staff. This advice was adopted hence all newly employed staffs of the University from November 2011 were required to visit the Optometry clinic for a mandatory eye test as part of the medical examination required for job placement. The purpose of this study was to report the oculo-visual findings of the new workers seen at the eye clinic.

\section{METHOD}

This was a retrospective study of the records of two thousand one hundred employed staff of the University of Benin, Benin City, Nigeria, who were employed between November 2011 and August 2014. As at the time of collection of these reported records, about two thousand one hundred and twenty eight candidates had been registered for eye test, but twenty eight of the records were not fully documented and so could not be included in the study. The newly employed staffs were examined at the Optometry Clinic of the University of Benin.

Of the 2100 case notes that were reviewed, 1203 (57.28\%) were males and 897 (42.71\%) were females. Their age ranged from 23 to 65 years with a mean age of $43 \pm 2.1$ years. Most were fresh employments by the University, a few were those who had retired from service and were coming back for temporary contract employment, while others were former casual workers who had now been given permanent placement. The basic tests that were carried out as part of the screening examination were distant visual acuity test at 6 meters and near visual acuity test at 0.4 meters.

This was done using the Snellen letter chart. Examination to assess the external ocular adnexa was done using a penlight. Confrontational visual fields test was done to assess whether the visual fields were full or constricted. Direct monocular ophthalmoscopy was done to assess the integrity of the interior segment of the eye. The cover test and Maddox rod tests were done to assess binocular status. Retinoscopy was done using a static retinoscope to determine the type and amount of refractive error present.

At the end of these tests, any subject who was suspected to have any form of ocular pathology or a refractive error that was uncorrected was usually referred and given appointment for a more comprehensive examination on another day.

\section{RESULTS}

Of the 2100 case notes that were reviewed, 1203 $(57.28 \%)$ were males and 897 (42.71\%) were females. Their age ranged from 23 to 65 years with a mean age of $43 \pm 2.1$ years. Majority of the workers $(41.1 \%)$ were between 41 to 50 years old. Details of age and sex distribution are shown in Table 1. 
Table 1 Age and Sex Distribution of Workers

\begin{tabular}{|l|l|l|l|l|l|l|}
\hline \multirow{2}{*}{$\begin{array}{l}\text { Age } \\
\text { Range }\end{array}$} & Male & $(897)$ & Female & $(1203)$ & Total & $(2100)$ \\
\hline $23-30$ & 197 & $(\%)$ & No & $(\%)$ & No & $(\%)$ \\
\hline $31-40$ & 137 & $(15.2)$ & 263 & $(21.0)$ & 450 & $(21.4)$ \\
\hline $41-50$ & 376 & $(42.0)$ & 487 & $(27.7)$ & 398 & $(19.0)$ \\
\hline $51-60$ & 164 & $(18.2)$ & 186 & $(15.5)$ & 863 & $(41.1)$ \\
\hline $61-70$ & 23 & $(2.6)$ & 16 & $(1.3)$ & 350 & $(16.6)$ \\
\hline & & & & & & $(1.9)$ \\
\hline
\end{tabular}

Confrontational fields test result was full for all the subjects. Visual findings from the various tests performed are outlined in Table 2.

Table 2 Visual Status with various tests conducted

\begin{tabular}{|l|l|l|l|l|l|l|}
\hline \multicolumn{2}{|l|}{ Tests } & \multicolumn{3}{|l|}{ Visual findings } & $\mathbf{( \% )}$ & \\
\hline versions & Smooth & 82.0 & Jerky & 10.0 & Nystagmic & 8.0 \\
\hline Cover test & Normal & 76.0 & Estropia & 5.0 & Exotropia & 19.0 \\
\hline Opthalmoscopy & Normal & 64.0 & Cataract & 5.0 & $\begin{array}{l}\text { Suspected } \\
\text { pathology }\end{array}$ & 11.0 \\
\hline Pupillary reflex & Normal & 96.0 & Weak & 4.0 & Absent & 0.0 \\
\hline Visual acuity & $>6 / 9$ & 51.0 & $6 / 9-6 / 18$ & 24.0 & $6 / 24-6 / 60$ & 25.0 \\
\hline Near refraction & $\begin{array}{l}\text { Presby } \\
\text { opic }\end{array}$ & 42.0 & \multicolumn{7}{|l|}{ Non Presbyopic } & 58.0 & \\
\hline
\end{tabular}

Refractive errors $25 \%$ and presbyopia $42.1 \%$ were the main visual problems recorded. The most common refractive error was hyperopia $26.8 \%$, followed by astigmatism $21.3 \%$ and myopia $9.6 \%$. This is shown in Table 3.

Table 3 Refractive Status of Workers

\begin{tabular}{|l|l|l|l|l|l|l|}
\hline $\begin{array}{l}\text { Refractive } \\
\text { Error }\end{array}$ & Male & $\mathbf{( n = 1 2 0 3 )}$ & Female & $(\mathbf{n = 8 9 7 )}$ & Total & $\mathbf{( = 2 1 0 0 )}$ \\
\hline & No & $(\%($ & No & $(\%)$ & No & $(\%)$ \\
\hline Myopia & 102 & $(8.5)$ & 100 & $(11.1)$ & 202 & $(9.6)$ \\
\hline Hyperopia & 365 & $(30.3)$ & 197 & $(22.0)$ & 562 & $(26.8)$ \\
\hline Astigmatism & 247 & $(20.5)$ & 200 & $(22.3)$ & 447 & $(21.3)$ \\
\hline Presbyopia & 489 & $(40.7)$ & 400 & $(44.6)$ & 889 & $(42.3)$ \\
\hline Total & 1203 & $(100.00)$ & 897 & $(100.0)$ & 2100 & $(100.0)$ \\
\hline
\end{tabular}

Ocular conditions that were common among the workers were itching/conjuctivitis $36.6 \%$, corneal disorders like pterygium and pingueculum $25.2 \%$ and bacterial infection was $21.1 \%$. A diagnosis of uveitis was made for $2.8 \%$ of the subjects from ophthalmoscopic examination of the eye and from the symptoms recorded from the subjects. Twenty nine $(1.4 \%)$ subjects were termed as glaucoma suspects because of the suspicious large cupping of between 0.4 to $0.6 \mathrm{cup} / \mathrm{disc}$ ratio and excavation of the optic nerve head observed in one or both eyes while performing ophthalmoscopy. Details are outlined in Table 4.

Fifty four percent (54\%) of the workers had never gone for an eye examination prior to the mandatory eye examination.
Among these new workers who had never gone for eye examination before now, 38\% were those given fresh employment while $16 \%$ were previous casual workers that were given permanent job placement.

Table 4 Ocular Findings among workers

\begin{tabular}{|l|l|l|l|l|l|l|}
\hline Diseases & Male & $\mathbf{( 8 9 7 )}$ & Female & $\mathbf{( 1 2 0 3 )}$ & Total & $\mathbf{( 2 1 0 0 )}$ \\
\hline & No & $\%$ & No & $\%$ & No & $\%$ \\
\hline Uveitis & 28 & $(3.12)$ & 31 & $(2.57)$ & 59 & $(2.80)$ \\
\hline Infection & 216 & $(24.08)$ & 226 & $(18.78)$ & 442 & $(21.05)$ \\
\hline Blepharitis & 24 & $2.56)$ & 20 & $(1.66)$ & 44 & $(2.09)$ \\
\hline $\begin{array}{l}\text { Retinitis } \\
\text { Pigmentosa }\end{array}$ & 3 & $(0.33)$ & 1 & $(0.08)$ & 4 & $(0.19)$ \\
\hline Foreign Body & 22 & $(2.45)$ & 28 & $(2.32)$ & 50 & $(2.38)$ \\
\hline Itching/conjuctivitis & 302 & $(33.66)$ & 468 & $(39.90)$ & 770 & $(36.66)$ \\
\hline Corneal Disorders & 321 & $(35.78)$ & 208 & $(17.29)$ & 529 & $(25.19$ \\
\hline Immature Cataract & 68 & $(7.58)$ & 34 & $(2.82)$ & 102 & $(4.85)$ \\
\hline Glaucoma suspect & 21 & $(2.34)$ & 8 & $(0.665)$ & 29 & $(1.38)$ \\
\hline
\end{tabular}

Eighteen per cent (18\%) of those who had gone for an eye examination before did not obtain the pair of glasses that was recommended for them. The reasons given for this included cost, convenience or lack of felt need.

\section{DISCUSSION}

The examination or screening of a newly hired employee's vision can provide important information to the company and to the worker ${ }^{20}$. Apart from the fact that the worker can be placed in a position that is best suited for his visual skills, the worker is also made aware of his ocular status. ${ }^{21}$ It can also serve to detect previously undiagnosed diseases or refractive errors as was the case in this study. Identifying and correcting even a small refractive error can greatly increase a worker's visual efficiency and productivity. ${ }^{22}$

It is important for adults to have eye examinations on a regular basis to be sure of a good eye health. Regular eye examinations are critical for detecting glaucoma, age-related macular degeneration (AMD), cataracts, diabetic retinopathy and other conditions that are age related. $^{23,24}$ This is particularly important if someone had risk factors or a family history of eye problems. ${ }^{25}$ Adults should see an eye doctor at least every two years and annually after the age of 60 . Unfortunately in this study, $54 \%$ of the workers had never gone for an eye examination prior to the mandatory eye examination. Vision standards are set for specific jobs to ensure that workers have the necessary vision skills to accomplish their required tasks in a safe and efficient manner. In the work environment for example, vision standards should be viewed as guidelines and not as absolute limits. ${ }^{26}$ 
When a worker fails to meet a vision standard, due to a specific visual impairment, particular consideration maybe given to ascertain if he or she can accomplish the tasks with optical aids. ${ }^{27}$ Very often when an individual fails to pass a vision test, a change in refractive correction or error, might be all that is needed. This often occurs when a person with beginning presbyopia is required to pass a near distance reading test. Reading glasses might be all that is required for the worker to pass the test and regain lost efficiency. As a follow up to the mandatory visual tests conducted for the newly employed workers of the University of Benin, all subjects who were suspected to have ocular pathology or uncorrected or under corrected refractive errors, were referred for a more comprehensive eye examination so that proper intervention and medication can be dispensed to treat their conditions.

The extent of visual field required in a worker is primarily an issue of safety. Take for instance in a construction site, where forklift operators often function in crowded environments where other workers are present. If there is a load blocking the forward view of the forklift, the operator may partially turn in the seat and drive backward, thus limiting the lateral extent of vision present on the side of the head facing the new direction of motion. ${ }^{28}$ A good visual field is required for this maneuvering, so as not to endanger the lives of those around. Fortunately in this study, all the subjects had full visual fields result.

One of the ways to assess a patient's workplace tasks is from their occupational history. ${ }^{29}$ The occupational history includes a complete description of both the visual task and the health hazards within the workplace environment. Completing an assessment of the patient's work environment and multiple workplace tasks should enable the Optometrist or Ophthalmologist to prescribe appropriate treatments to maximize the patient's visual efficiency.

Eye care professionals encounter patients in wide varieties of occupations and workplace environments. The time of the comprehensive eye examination is the best time for the Optometrist or Ophthalmologist to assess all aspects of the relationship between work and vision, visual performance, eye safety and health. This relationship would include the worker's eyes and visual system, as well as the worker and the workplace environment. ${ }^{30-32}$
In many low and middle-income countries, there are inadequate refractive error services for the many people who are currently either blind or visually impaired because they lack a pair of spectacles.

The prioritization of refractive error and low vision services within VISION 2020: The Right to Sight has provided an impetus and framework for the development of refractive error program to meet this need for services.

To ensure the success of a refractive error program, there have to be enough qualified personnel, usually Optometrists and Ophthalmologists, with the right skills in order to provide refraction services throughout the program. ${ }^{33}$ Therefore, careful thought should be given to setting up an appropriate training program that will support the human resource needs of a refractive error program. ${ }^{34}$

In developed countries where workers are made to go for yearly physical examinations, companies recognize the importance of visual performance at every level of their operations. They know that vision significantly influences their employee's ability to operate with fewer accidents and produce higher quality work with less effort and fewer errors. However, this is not so in developing or low resource country like Nigeria where such conditions like routine eye examinations are not put in place or required during employment exercises.

The significance of this study is that it will highlight the need for proper eye examination conducted by eye care personnel to be integrated into the regular medical screening that is usually recommended for newly employed workers before job placement. This will ensure that workers are operating at the highest level of efficiency when placed in the different aspect of the production process or the rendering of services in employment. It is hoped that with more studies like this, awareness will increase on the need to put such matters into effect, so as to get the full potentials from employed personnel.

The limitation of this study was that because it was done retrospectively, conclusions can only be drawn on the available information as recorded in the record files of the subjects.

\section{REFERENCES}

1. Leonard R, D'Allura T, Horowitz A. Factors associated with employment among persons who have vision impairment: A follow-up of vocational placement referrals. J Voc Rehab. 1999; 12(1), 3343. 
2. 8. Baldwin ML, Schumacher EJ. A note on job mobility among workers with disabilities. Industrial Relations: J Econ and Soc. 2002: 41(3): 430441.

3. Capella, M. Predicting earnings of vocational rehabilitation clients with visual impairments. $J$ Rehab. 2001; 67(4), 43-47.

4. Fireison C, Moore J. Employment Outcomes and Educational Backgrounds of Legally Blind Adults Employed in Sheltered Industrial Settings. J Visual Impair Blindness. 1998; 92(11), 740-47.

5. Capella-McDonnall M. Predictors of competitive employment for blind and visually impaired consumers of vocational rehabilitation services. $J$ Visual Impair Blindness. 2005; 99(5), 303-315.

6. Bell EC. Competitive employment for consumers who are legally blind: A 10-year retrospective study. J Rehab Res Dev. 2010; 47(2), 109-116.

7. Bell EC. Mentoring transition-age youth with blindness. J Special Edu. 2012; 46(3), 170-179.

8. Udeh NN, Eze BI, Onwubiko SN, Arinze OC, Onwasigwe EN, Umeh RE. Oculocutaneous Albinism: Identifying and overcoming Barriers to Vision care in a Nigerian Population. J Comm Health. 2013; 102:47-52.

9. Darensbourg B. Predictors of competitive employment of VR consumers with blindness or visual impairments. J Voc Rehab. 2013; 38(1), 29-34.

10. Fafowora OF. Prevalence of blindness in rural ophthalmically underserved Nigerian community. West Afr Med J. 1996; 15:228-231.

11. McDonnall M, Crudden A. Factors affecting the successful employment of transition-age youths with visual impairments. J Visual Impair Blindness. 2009; 103(6), 329-341.

12. Jeanmarie K, Strauser DR. Job readiness, selfefficacy and work personality: A comparison of trainee and instructor perceptions. $J$ Voc Rehab. 2000; 14(1) 13-21.

13. Kovai V, Krishnaiah S, Shamanna B R, Thomas R, Roa G N. Barriers to accessing eye care services among visually impaired population in rural Andhra Pradesh, South India. Indian J Ophthalmol. 2007; 55:365-371.

14. Ebeigbe JA and Ovenseri-ogbomo GO. Barriers to utilization of eye care services in rural communities in Edo State. Borno med J. 2014; 11(2) 98104.

15. Congdon N, O'Colmain B, Klaver CC. Causes and Prevalence of Visual Impairment Among Adults in the United States. Arch Ophthalmol. 2004;122(4): 477-85.
16. Ebeigbe JA, kio FE. Refractive Error Blindness in a Rural Community in Edo State, Nigeria. Afscope. 2006; (2) 1: 52-55.

17. Golub DB. A model of successful work experience for employees who are visually impaired: The results of a study. J Visual Impair Blindness. 2006; 100(12), 715-725.

18. Cavenaugh BS, Giesen JM, Pierce S J. Rehabilitation of visually impaired persons in separate and general agencies. J Visual Impair Blindness. 2000; 94(3), 133-145.

19. Ntsoane MD, Oduntan OA, Mpolokeng BL. Utilisation of public eye care services by the rural community residents in the Capricorn district, Limpopo Province, South Africa. Afr $J$ Prm Health Care Fam Med. 2012;4(1) 123-127.

20. Crudden A, McBroom L. Barriers to employment: A survey of employed persons who are visually impaired. J Visual Impair Blindness. 1999; 93(6), 341-350.

21. Martz E, Xu Y. Person-related and service-related factors predicting employment of individuals with disabilities. J Voc Rehab. 2008; 28(2), 97-104.

22. Ozawa M, Yeo Y. Work Status and Work Performance of People With Disabilities: An Empirical Study. J Disability Policy Studies. 2006; 17(3), 180-190.

23. Randolph DS. Predicting the effect of disability on employment status and income. Work: J Prevention, Assessment and Rehabilitation. 2004; 23(3), 257-266.

24. Nagle KM. Transition to employment and community life for youths with visual impairments: Current status and future directions. $J$ Visual Impair Blindness. 2001; 95(12), 725-738.

25. Warren-Peace P. Models that predict competitive employment outcomes in the United States Federal/State vocational rehabilitation program for clients who are blind and clients with other disabilities. Dissertation Abstracts International: Section A. Humanities and Social Science. 2009; 70(4-A), 1181.

26. Miller J. The Role of Orientation and Mobility Instructors and Rehabilitation Teachers in Enhancing Employment Opportunities for Persons Who Are Visually Impaired. J Visual Impair Blindness. 2002; 96(12), 852-55.

27. Lee PP, Feldman ZW, Ostermann J, Brown DS, Sloan FA. Longitudinal Prevalence of Major Eye Diseases. Arch Ophthalmol. 2003; 121(9): 130310.

28. Odom JV. Vision, Visual Needs and Quality of Life of Older People in Rural Environments: A 
Report and Synthesis of a Meeting. J Rural Health. 2001; 17(4): 360-63.

29. Brown AF. Need for Eye Care Among Older Adults with Diabetes Mellitus in Fee-for-Service and Managed Medicare. Arch Ophthalmol. 2005; 123(5): 669-75.

30. Goldzweig CL. Preventing and Managing Visual Disability in Primary Care: Clinical Applications. JAMA. 2004: 291(12): 1497-1502.

31. Wang F, Ford D, Tielsch JM, Quigley HA, Whelton PK. Undetected Eye Disease in a Primary
Care Clinic Population. Arch Intern Med. 1994; 154(16):1821-28.

32. Barry RJ, Murray PI. Unregistered visual impairment: is registration a failing system? $\mathrm{Br} J \mathrm{Oph}$ thalmol. 2005; 89:995-8.

33. 33.Bunce C, Wormald R. Causes of blind certifications in England and Wales: April 1999-March 2000. Eye. 2008; 22:905-11. 